\title{
ESTUDO DA VIABILIDADE DE PRODUÇÃO DE TIJOLO MODULAR COMPOSTO POR RESÍDUO DAA FABRICAÇÃO DE PAPEL E CIMENTO*
}

\author{
Wellington Fernandes Junior ${ }^{1}$ \\ Matias da Matta Duarte Theophilo ${ }^{1}$ \\ Jonas Alexandre ${ }^{1}$ \\ Bruno Rangel França ${ }^{1}$ \\ Euzébio Bernabé Zanelato ${ }^{1}$ \\ Sergio Rafael Cortes de Oliveira ${ }^{2}$ \\ Afonso Rangel Garcez de Azevedo ${ }^{1}$ \\ Sergio Neves Monteiro ${ }^{3}$
}

\section{Resumo}

O objetivo do presente estudo é avaliar a viabilidade do emprego do resíduo sólido industrial proveniente da fabricação do papel na produção de blocos de resíduocimento. Foi utilizado o resíduo gerado pela Companhia Paduana de Papeis COPAPA. Esta empresa, situada no município de Santo Antônio de Pádua e responsável por produzir 36.000 toneladas de papeis por ano, gera cerca de 13.320 ton/ano de resíduo, que hoje não tem um destino adequado. De acordo com esta demanda, surge à necessidade do estudo de incorporação do resíduo proveniente da indústria de papel. Foram confeccionados blocos com diferentes proporções de resíduo e cimento e realizados ensaios de resistência à compressão, absorção de água e durabilidade por ciclos de molhagem e secagem para cada um dos traços e diferentes tempos de cura. Com os resultados obtidos, verificou-se a viabilidade do uso do resíduo para produção dos blocos.

Palavras-chave:Bloco estrutural, Durabilidade, Copapa, Resíduo-cimento.

\section{STUDY OF THE FEASIBILITY OF PRODUCTION OF MODULAR BRICK COMPOSED OF PAPER MANUFACTURING RESIDUE AND CEMENT}

\begin{abstract}
The objective is to evaluate the feasibility of using industrial solid waste from paper manufacturing in the production of cement-residue blocks. Waste generated by Companhia Paduana de Papeis - COPAPA was used This company, located in the city of Santo Antônio de Pádua and responsible for 36,000 tons of paper manufactured per year, generates around 13,320 tons of waste, which today does not have a suitable destination. According to this demand, there is a need to study the incorporation of waste from the paper industry. Blocks with different ratios of residue and cement were made and tests such as compressive strength, water absorption and durability were performed by wetting and drying cycles for each of the traces and different curing times. With the results obtained, it was verified the viability of using of the residue for the production of blocks.
\end{abstract}

Keywords: Structural block; Durability; Copapa; Cement-residue.

Universidade Estadual do Norte Fluminense Darcy Ribeiro (UENF);

Instituto Federal de Educação, Ciência e Tecnologia Fluminense (IFF);

Instituto Militar de Engenharia (IME). 


\section{INTRODUÇÃO}

O Brasil passa por uma grave crise financeira e um dos setores mais afetados é o setor da construção civil, onde há inúmeras obras paralisadas. Isso deve-se a falta de consumidores também afetados pela crise e consequentemente por falta de dinheiro das construtoras por falta de consumidores. Uma das alternativas para driblar a crise é a redução de despesas nas obras, mas isso acarretaria numa mão de obra menos qualificada e materiais de má qualidade. Numa obra, 4 a $8 \%$ do valor total é gasto com alvenaria. Essa alvenaria é feita com tijolos cerâmicos, que são provenientes de uma matéria-prima não renovável e sua fabricação tem um custo elevado, além de ser poluente, devido a queima de lenha.

Paralelo a isso, há outro grande problema, o descarte de resíduos sólidos. A evolutiva degradação ambiental e a carência dos recursos naturais causadas não só pela exploração indiscriminada, mas principalmente, pela disposição inadequada de resíduos das atividades humanas no ambiente, e a busca por alternativas visando reverter essa situação são os temas dentre os mais discutidos atualmente. Ao atuar sem o licenciamento ambiental, a empresa torna-se alvo dos órgãos regulatórios e de fiscalização, os quais têm plenos poderes para autuar os estabelecimentos, aplicando multas ou sanções mais graves, e para interditar a atividade, caso as irregularidades persistam (BRACELPA, 2011).

A produção de resíduos pelas indústrias de papel e celulose vem crescendo continuamente, gerando gastos com estocagem ou aumentando os impactos ambientais, visto que estes materiais são destinados aos aterros. O aproveitamento desses resíduos como material de construção para a produção de novas tecnologias para a construção civil representa a minimização dos danos ambientais, além de ser uma alternativa para a redução do déficit habitacional. Soma-se a isso o fato de que o uso de blocos de solo-cimento é considerado um método construtivo mais barato do que o convencional, visto que uma das matérias-primas, o solo, é abundante (RODRIGUES, 2008).

A necessidade de atender às exigências de manejo adequado dos resíduos sólidos industriais impostas pelas leis ambientais do País deu origem ao presente estudo, que tem por objetivo avaliar a viabilidade do emprego do resíduo sólido industrial proveniente da produção do papel na produção de blocos de resíduo-cimento. Foi utilizado o resíduo gerado pela Companhia Paduana de Papéis - COPAPA, empresa situada no município de Santo Antônio de Pádua, que produz cerca de 36.000 toneladas de papeis por ano, juntamente com esta produção são gerados cerca de 13.320 ton/ano de resíduo, que hoje não tem um destino adequado.

Levando-se em consideração a necessidade de preservação ambiental, a tendência de escassez dos recursos naturais e o acúmulo crescente resíduos industriais, é essencial que a construção civil adquira novos conceitos e soluções técnicas visando a sustentabilidade de suas atividades.

Visando uma alternativa sustentável para o aproveitamento do resíduo, mas ao mesmo tempo atendendo as especificações impostas pela Norma Brasileira Regulamentadora para tijolos de solo-cimento, a proposta do presente trabalho é avaliar o aproveitamento do resíduo da fabricação de papel misturado com cimento para confecção de tijolos modulares prensados com dimensões de $30 \mathrm{~cm} \times 15 \mathrm{~cm} \times 7 \mathrm{~cm}$, de modo a reduzir os custos da obra e os impactos ambientais do método de fabricação de tijolos convencionais.

Os tijolos modulares de resíduo-cimento apresentam diversas vantagens, das quais podem se destacar as seguintes: 
- Produto ecologicamente correto

- Podem ser produzidos no próprio local de matéria prima;

- Requerem argamassa e revestimento de espessuras mínimas e uniformes;

- O revestimento pode ser dispensado, desde que seja protegido da ação direta da água;

- Consomem apenas, cerca de 0,1 MJ/kg de energia, enquanto os tijolos cerâmicos, com a queima em fornos, consomem em torno de 8 a 16 vezes mais energia.

\section{MATERIAIS E MÉTODOS}

Os tijolos que foram produzidos neste trabalho são compostos pelos materiais a seguir:

\subsection{Cimento Portland}

Foi utilizado o cimento Portland do tipo CP V-ARI da marca Votoran, cuja caracterização física e química foi realizada pelo fabricante (Tabela 1) e foi verificado que estava dentro das especificações de cimento CP V-ARI impostas pela NBR 5733, conforme Tabela 2.

Tabela 1. Especificações físicas e químicas do cimento CP-V ARI Votoran

Tabela 1. Propriedades fisico-químicas do cimento

\begin{tabular}{|c|c|}
\hline \multicolumn{2}{|c|}{ Ensaios Físicos } \\
\hline Resíduo na peneira $\mathrm{ABNT} \mathrm{n}^{\circ} 200(\%)$ & 0,08 \\
\hline Residuo na peneira ABNT n $325(\%)$ & 1,76 \\
\hline Área especifica Blaine $\left(\mathrm{m}^{2} \mathrm{~kg}^{-1}\right)$ & 4339,00 \\
\hline Início de pega (min) & 184,00 \\
\hline Fim de pega (min) & 261,00 \\
\hline Expansibilidade a quente (mm) & 0,00 \\
\hline Resistência a compressão (MPa) - $1 \mathrm{~d}$ & 26,50 \\
\hline Resistência a compressão (MPa) - 3 d & 40,50 \\
\hline Resistência a compressão (MPa) - $7 \mathrm{~d}$ & 43,10 \\
\hline Resistência a compressão (MPa) - $28 \mathrm{~d}$ & 54,10 \\
\hline Massa específica $\left(\mathrm{g} \mathrm{dm}^{-3}\right)$ & 3,130 \\
\hline \multicolumn{2}{|c|}{ Ensaios Químicos } \\
\hline Perda ao fogo $(\%)$ & 2,88 \\
\hline $\mathrm{C}_{2} \mathrm{~S}(\%)$ & 5,44 \\
\hline $\mathrm{C}_{3} \mathrm{~S}(\%)$ & 64,58 \\
\hline $\mathrm{C}_{3} \mathrm{~A}(\%)$ & 6,78 \\
\hline $\mathrm{CaO}$ livre $(\%)$ & 0,73 \\
\hline MgO livre (\%) & 1,99 \\
\hline $\mathrm{K}_{2} \mathrm{O}(\%)$ & 0,81 \\
\hline $\mathrm{Na}_{2} \mathrm{O}(\%)$ & 0,03 \\
\hline $\mathrm{SO}_{3}(\%)$ & 3,00 \\
\hline Residuo insolúvel (\%) & 0,34 \\
\hline Água de consistência (\%) & 28,15 \\
\hline
\end{tabular}


Tabela 2. Especificações físicas e químicas para cimento CP V-ARI.

\begin{tabular}{|c|c|c|}
\hline \multirow{2}{*}{\begin{tabular}{|l}
\multicolumn{2}{|c}{ CP V-ARI } \\
ENSAIOS FÍsICOS \\
\end{tabular}} & \multicolumn{2}{|c|}{ Especificações ABNT } \\
\hline & & \\
\hline Blaine $\left(\mathrm{cm}^{2} / \mathrm{g}\right)$ & $\geq 3000$ & NBR NM 76 \\
\hline Tempo de início de pega (h:min) & $\geq 1$ & NBR NM 65 \\
\hline Tempo de fim de pega (h:min) & $\leq 10$ & NBR NM 65 \\
\hline Finura na peneira \# 200 (\%) & $\leq 6,0$ & NBR 11579 \\
\hline Finura na peneira \# 325 (\%) & - & NBR 9202 \\
\hline Expansibilidade a quente (mm) & $\leq 5,0$ & NBR 11582 \\
\hline Consistência normal (\%) & - & NBR NM 43 \\
\hline Resistência à compressão 1 dia (MPa) & $\geq 14,0$ & NBR 7215 \\
\hline Resistência à compressão 3 dias (MPa) & $\geq 24,0$ & NBR 7215 \\
\hline Resistência à compressão 7 dias (MPa) & $\geq 34,0$ & NBR 7215 \\
\hline Resistência à compressão 28 dias (MPa) & - & NBR 7215 \\
\hline ENSAIOS QUÍMICOS & & \\
\hline Perda ao fogo (\%) & $\leq 4,5$ & NBR 5743 \\
\hline Resíduo insolúvel (\%) & $\leq 1,0$ & NBR 5744 \\
\hline Trióxido de enxofre $-\mathrm{SO}_{3}(\%)$ & $\leq 3,5$ & NBR 5745 \\
\hline Óxido de cálcio livre - CaO Livre (\%) & - & NBR 7227 \\
\hline Óxido de magnésio - MgO (\%) & $\leq 6,5$ & NBR 9203 \\
\hline Óxido de alumínio $-\mathrm{Al}_{2} \mathrm{O}_{3}(\%)$ & - & NBR 9203 \\
\hline Óxido de silício - $\mathrm{SiO}_{2}(\%)$ & - & NBR 9203 \\
\hline Óxido de ferro $-\mathrm{Fe}_{2} \mathrm{O}_{3}(\%)$ & - & NBR 9203 \\
\hline Óxido de cálcio - CaO (\%) & - & NBR 9203 \\
\hline Equivalente alcalino (\%) & - & - \\
\hline
\end{tabular}

A escolha do cimento Portland CP V-ARI deve-se a sua capacidade de atingir altas resistências já nos primeiros dias da aplicação. O desenvolvimento da alta resistência inicial é conseguido pela utilização de uma dosagem diferente de calcário e argila na produção do clínquer, bem como pela moagem mais fina do cimento, de modo que, ao reagir com a água, ele adquira elevadas resistências, com maior velocidade. O clínquer é o mesmo utilizado para a fabricação de um cimento convencional, mas permanece no moinho por um tempo mais prolongado. O cimento continua ganhando resistência até os 28 dias, atingindo valores mais elevados que os demais. O CP V-ARI assim como o CP-I é um cimento puro, ou seja, não contém adições. O que o diferencia deste último é o processo de dosagem e produção do clínquer. O CP V-ARI é produzido com um clínquer de dosagem diferenciada de calcário e argila se comparado aos demais tipos de cimento e com moagem mais fina. Esta diferença de produção confere a este tipo de cimento uma alta resistência inicial, podendo atingir 26MPa de resistência à compressão em apenas 1 dia de idade.

\subsection{Resíduo da Fabricação de Papel}

O resíduo utilizado é lodo primário proveniente da fabricação de papel (Figura 1) e foi fornecido e transportado pela Companhia Paduana de Papéis (COPAPA) até o campus da Universidade Estadual do Norte Fluminense (UENF). 
Figura 1. Resíduo da fabricação de papel cedido pela COPAPA.

O material passou por um processo de secagem, onde foi exposto ao sol até que estivesse seco o suficiente para ser triturado. Em seguida passou por um triturador com regulagem de tamanho dos grãos, em que foi utilizada uma regulagem para que todo o material passasse pela peneira $\mathrm{n}^{\circ} 10$, a fim de diminuir o número de vazios que seriam formados caso fosse utilizado material que tenha grãos maiores que 2,0 $\mathrm{mm}$.

\section{3 Água}

A água utilizada é proveniente da Concessionária Águas do Paraíba, localizada no município de Campos dos Goytacazes.

\subsection{Metodologia}

\subsubsection{Análise Granulométrica}

A determinação do tamanho das partículas é de extrema importância para definição da proporção de cada material para confecção dos blocos. A curva de distribuição granulométrica do resíduo foi determinada segundo a prescrição da norma NBR 7181 (ABNT, 1984), que consiste na combinação entre o peneiramento do material e sua sedimentação. Os ensaios foram realizados no Laboratório de Solos do LECIV/UENF.

\subsubsection{Limites de Atterberg}

A determinação da consistência do resíduo define a umidade do material através de métodos empíricos como limite de liquidez (LL), o limite de plasticidade (LP), e índice de plasticidade (IP). Os ensaios para determinação dos Limites de Atterberg foram executados no Laboratório de Solos do LECIV/UENF, de acordo com as prescrições da norma NBR 6459 (ABNT, 1984) e NBR 7180 (ABNT, 1984). 


\subsubsection{Massa Específica Real dos Grãos}

A determinação da massa específica real dos grãos do resíduo foi realizada de acordo com as normas NBR 6508 (ABNT, 1984) e NBR 6457 (ABNT, 1986). Este ensaio foi executado no Laboratório de Solos do LECIV/UENF.

\subsubsection{Espectroscopia de raios X (EDX)}

A análise química apresenta grande importância para identificação mineralógica dos materiais, visto que auxilia no conhecimento das porcentagens de cada óxido presente em sua composição. Apesar da análise química não proporcionar uma avaliação completa em relação a composição mineralógica e das propriedades físico-químicas de cada material, ela indica dados importantes que contribuem na identificação dos minerais contidos na amostra. A composição química da matéria prima utilizada foi obtida através de análise realizada na Oficina de Microanálise do Laboratório de Engenharia Civil LECIV/UENF, com o equipamento Shimadzu EDX700 .

\subsubsection{Definição dos Traços}

Foram analisadas diferentes proporções de cada material em três traços, alterando a quantidade de cimento e de resíduo em cada um dos traços. Foram utilizados traços com proporção de $20 \%, 30 \%$ e $40 \%$ de cimento em relação a massa da mistura, com traços em massa de, respectivamente, 1:4, 1:2,3 e 1:1,5 (cimento:resíduo).

Após definição dos traços, foi determinada a umidade ótima para cada traço. Essa determinação foi feita no Laboratório de Engenharia Civil da UENF, onde pequenas quantidades do material foram totalmente secas em estufa a uma temperatura $100^{\circ} \mathrm{C}$ até constância da massa. Após secagem, os materiais foram homogeneizados nas suas devidas proporções para cada traço e aos poucos acrescentou-se água com borrifador industrial até chegar ao ponto de "farofa úmida".

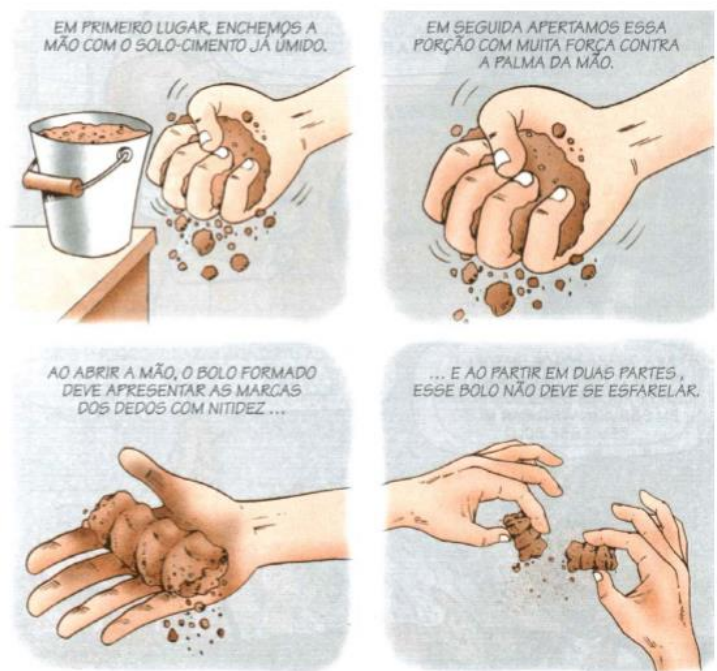

Figura 2. Determinação da umidade ótima da mistura solo-cimento

\subsubsection{Fabricação dos Tijolos}

Após definir as proporções de materiais de cada traço, os materiais foram pesados em balança digital. Foi calculada a umidade do resíduo. A umidade encontrada 
definiu a quantidade de água que deveria ser descontada da quantidade de água ideal caso a amostra estivesse totalmente seca, a fim de chegar na umidade ótima. Em seguida foram levados para um misturador até que a mistura ficasse homogeneizada. Foi utilizada uma bomba costal para umedecer a mistura até que chegasse a umidade ideal, formando uma farofa úmida. Utilizou-se a bomba costal a fim de evitar a formação de grumos na mistura, que seriam formados caso a água fosse acrescentada de uma só vez.

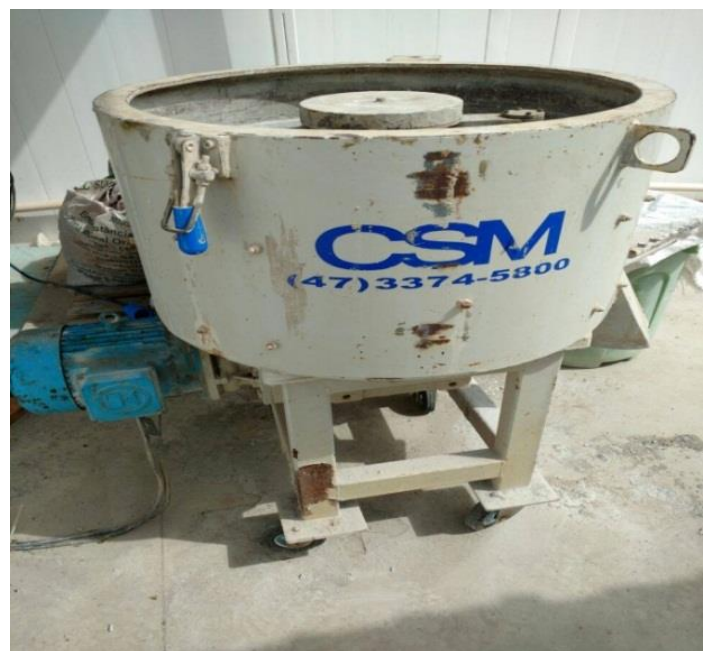

Figura 3. Misturador onde foi feita a mistura resíduo-cimento.

\subsubsection{Prensagem dos Tijolos}

A mistura na umidade ideal, conforme a NBR 10833 (ABNT, 2012), foi levada à prensa hidráulica modelo 7000 Turbo II da marca Ecomáquinas (Figura 4), com capacidade de produção de dois blocos por prensagem.

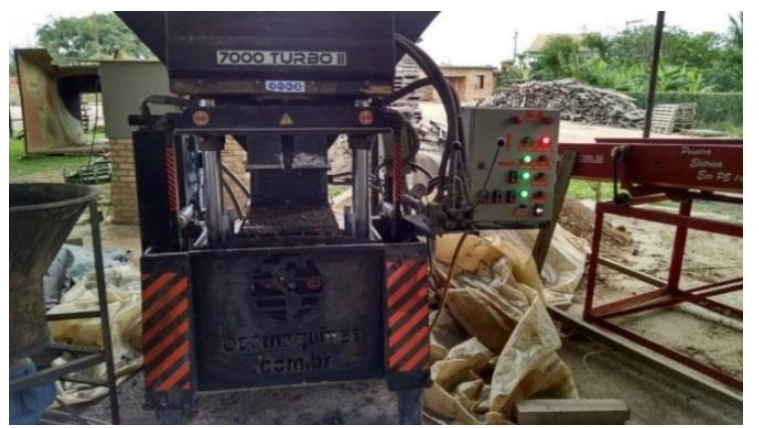

Figura 4. Prensa Hidráulica 7000 Turbo II, da Ecomáquinas.

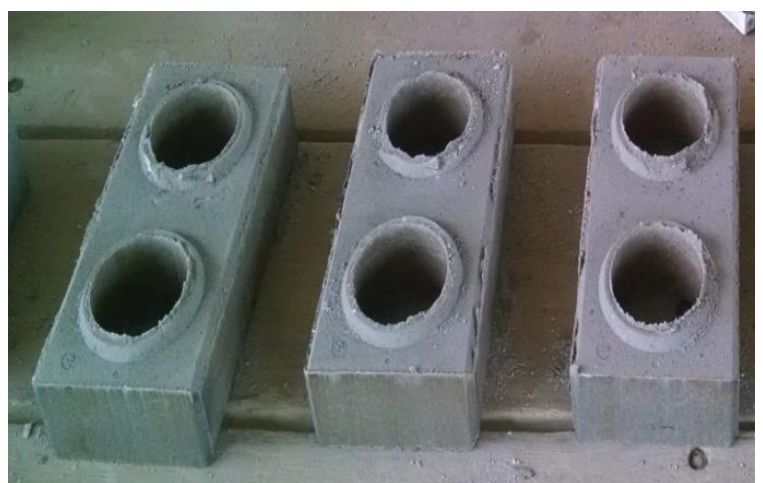

Figura 5. Tijolos de resíduo-cimento após a prensagem 
Após a prensagem, os tijolos foram curados em câmara úmida para obter ganho de resistência e só foram retirados para ensaios em idades pré-determinadas.

\subsubsection{Absorção de Água}

Após um período de cura de 7, 14 e 28 dias em câmara úmida, seis tijolos de cada traço foram imersos na água por 24 horas e depois pesados em uma balança de precisão. Após pesagem, foram secos em estufa em temperatura de $105^{\circ} \mathrm{C}$ a $110^{\circ} \mathrm{C}$ até constância da massa, para determinação da massa seca. Após a pesagem do tijolo seco, foi calculada a absorção de água de acordo com a NBR 10836 (ABNT, 1994), onde regulamenta que os tijolos devem ter absorção de água média menor ou igual a $20 \%$ da sua massa seca.

\subsubsection{Resistência à Compressão}

Para os ensaios de resistência à compressão, seis tijolos de cada traço foram ensaiados em três diferentes idades de cura (7,14 e 28 dias) a fim de acompanhar 0 ganho de resistência ao longo de 28 dias. Seguindo a NBR 10836 (ABNT, 1994), os tijolos foram devidamente capeados com uma pasta a base de cimento e água a fim de uniformizar a base e a parte superior do tijolo. Os tijolos foram ensaiados em uma prensa da marca SOLOTEST disponível no LECIV/UENF. A resistência à compressão média dos blocos deve ser maior ou igual a 2,0 MPa.

\section{RESULTADOS E DISCUSSÃO}

\subsection{Análise granulométrica}

Foi constatado através do ensaio de granulometria que o resíduo de papel utilizado se apresentou como um material silte-argiloso com massa específica dos sólidos igual a 1,95 g/cm³ , conforme granulometria apresentada na Tabela 3.

Tabela 3. Granulometria do resíduo da fabricação de papel

\begin{tabular}{|c|c|c|}
\hline \multicolumn{3}{|c|}{ GRANULOMETRIA } \\
\hline \multirow{2}{*}{ AREIA } & MÉDIA & $2,80 \%$ \\
\cline { 2 - 3 } & FINA & $8,40 \%$ \\
\hline \multicolumn{2}{|c|}{ SILTE } & $50,90 \%$ \\
\hline \multicolumn{2}{|c|}{ ARGILA } & $37,90 \%$ \\
\hline
\end{tabular}

\subsection{Limites de Atterberg}

O resultado obtido no ensaio de limite de liquidez (LL) para o resíduo utilizado pode ser observado na Tabela 4. O resíduo analisado atende ao requisito da NBR 10832 (ABNT, 1989) em relação ao limite de liquidez, sendo inferior ao máximo permitido de 45\%, e atende ao requisito da NBR 10832 (ABNT, 1989) em relação ao índice de plasticidade, com valor inferior ao máximo permitido, de $18 \%$. 
Tabela 4. Limites de Atterberg do resíduo da fabricação papel.

\begin{tabular}{|c|c|c|}
\hline \multicolumn{3}{|c|}{ LIMITES DE ATTERBERG } \\
\hline LL & LP & IP \\
\hline $41,10 \%$ & $24,10 \%$ & $17,00 \%$ \\
\hline
\end{tabular}

\subsection{Espectroscopia de raios X (EDX)}

Quanto à composição química, a Tabela 5 mostra que o resíduo é constituído predominantemente de óxido de cálcio, sílica, alumina e carbono orgânico. O $\mathrm{CaO}$ está associado à calcita. Já o SiO2 e o Al2O3, estão combinados formando a estrutura da caulinita. O carbono está associado à presença de celulose. Os demais óxidos presentes, $\mathrm{MgO}$, $\mathrm{TiO} 2$ e Fe2O3, são possivelmente de impurezas presentes no caulim e na calcita.

Tabela 5. Espectroscopia de raios $X$ do resíduo da fabricação de papel.

\begin{tabular}{|c|c|c|c|c|c|c|}
\hline \multicolumn{7}{|c|}{ ESPECTROSCOPIA DE RAIOS X } \\
\hline $\mathrm{SiO}_{2}$ & $\mathrm{Al} 2 \mathrm{O} 3$ & $\mathrm{CaO}$ & $\mathrm{MgO}$ & $\mathrm{TiO} 2$ & $\mathrm{Fe} 2 \mathrm{O} 3$ & $\mathrm{C}$ \\
\hline $22,53 \%$ & $18,10 \%$ & $37,87 \%$ & $2,05 \%$ & $0,56 \%$ & $0,82 \%$ & $18,12 \%$ \\
\hline
\end{tabular}

\subsection{Resistência à compressão}

Os tijolos foram ensaiados nas três diferentes idades após cura em câmara úmida. $A$ figura 6 mostra o resultado médio da resistência à compressão dos traços em três diferentes idades de cura. $O$ resultado aponta o valor médio da resistência à compressão obtido a partir de ensaio de seis tijolos de cada traço para cada idade. Nota-se que todas as proporções atendem ao requisito da NBR 10836 (ABNT, 1994b) em relação à resistência à compressão, já que o valor médio de resistência à compressão aos 28 dias de idade dos tijolos nessas proporções foi superior ao mínimo permitido, de 2,0 MPa.

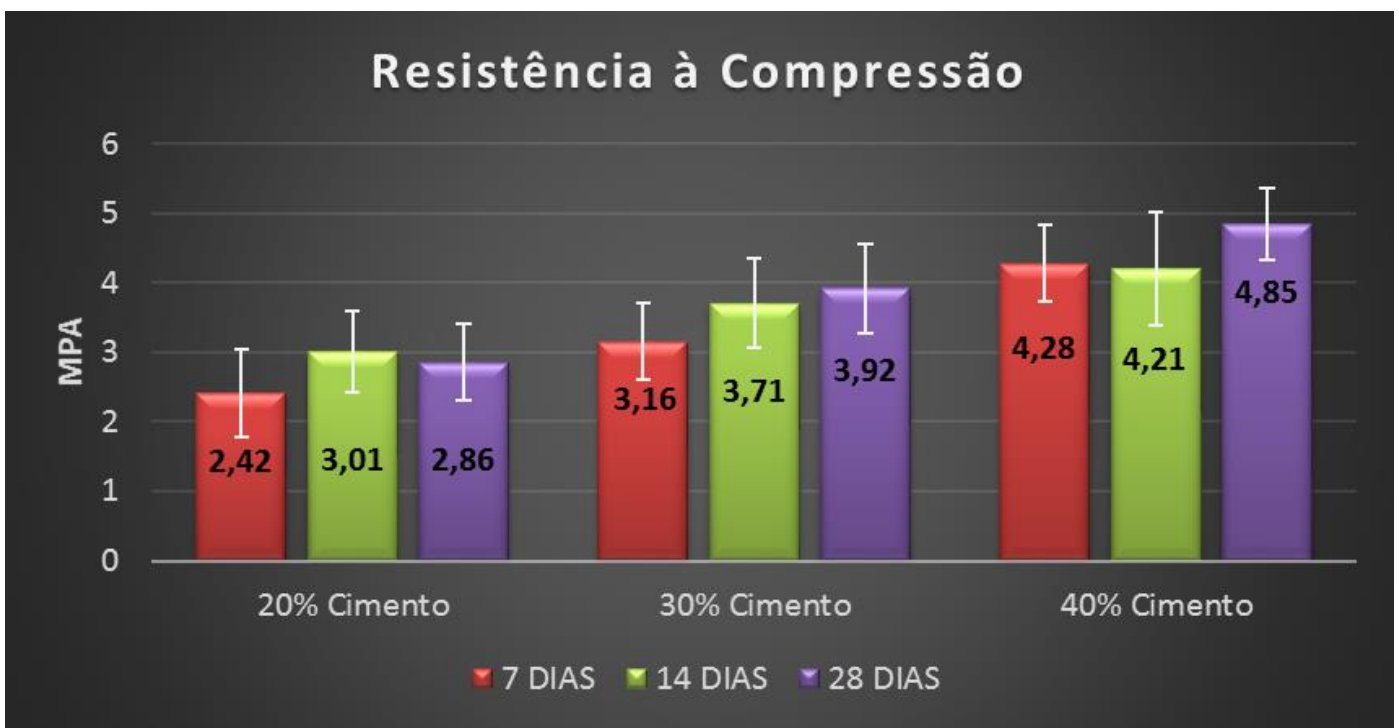

Figura 6. Resistência à compressão dos tijolos em diferentes idades de cura. 


\subsection{Absorção de água}

Os tijolos foram ensaiados nas três diferentes idades após cura em câmara úmida. A figura 7 mostra o resultado médio de absorção de água dos traços em três diferentes idades de cura. O resultado aponta o valor médio da absorção de água obtido a partir de ensaio de seis tijolos de cada traço para cada idade. Nota-se que apenas o traço com proporção de $40 \%$ de cimento e $60 \%$ de resíduo atende ao requisito da NBR 10836 (ABNT, 1994b) em relação à absorção de água, já que o valor médio de absorção de água aos 28 dias de idade dos tijolos nessas proporções foi inferior ao máximo permitido, de $20 \%$.

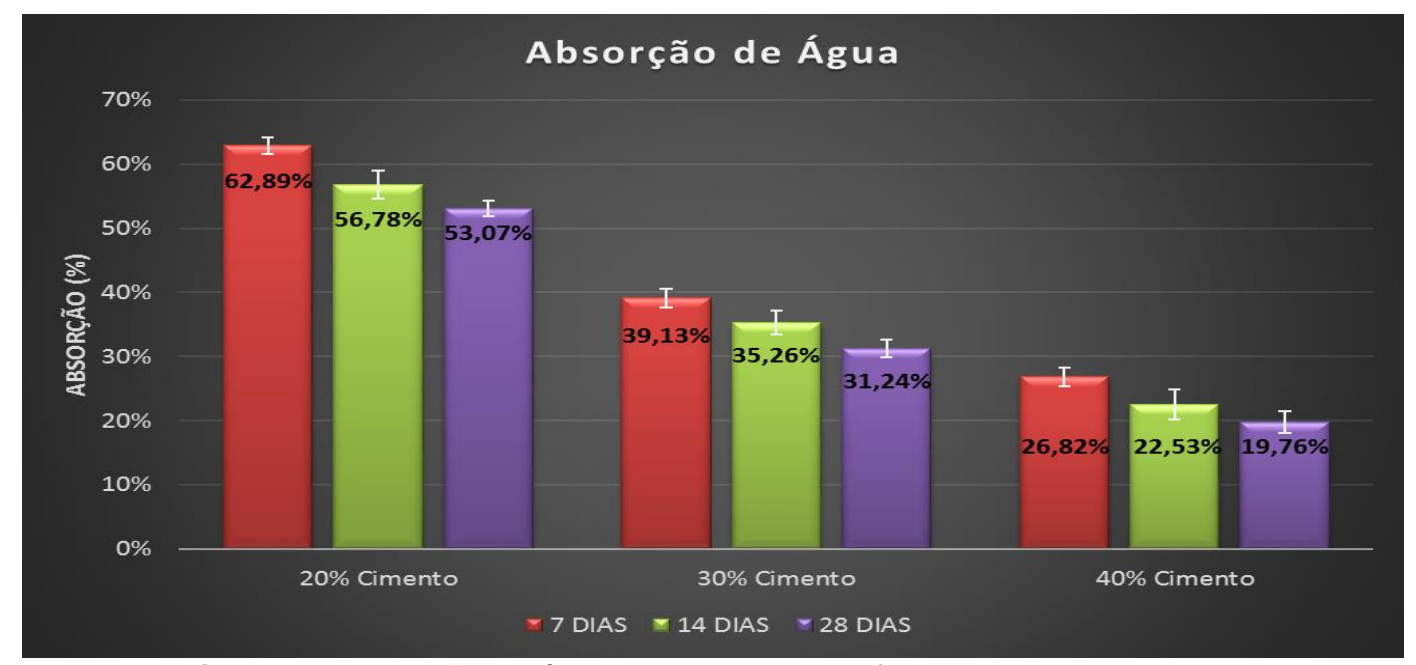

Figura 7. Absorção de água dos tijolos em diferentes idades de cura.

\section{CONCLUSÕES}

- Em relação à caracterização física, pode-se concluir que o resíduo utilizado atende às exigências da NBR 10832 (ABNT, 1989).

- Com o objetivo de verificar a maior quantidade de resíduo que poderia ser utilizado, respeitando as exigências normativas, todos teores atenderam às exigências da NBR 10836 (ABNT, 1994b) em relação a resistência à compressão. Porém, apenas o traço com proporção, em massa, de 1:1,5 atendeu as exigências para absorção de água.

- A presente pesquisa enquadra-se no contexto da sustentabilidade na construção civil pela possibilidade de reciclagem de material, pela dispensa de queima na produção dos tijolos e pela minimização dos desperdícios no canteiro de obras associada ao sistema modular, contribuindo, dessa forma, para a diminuição da degradação do meio ambiente e do déficit habitacional.

- Portanto, a incorporação do resíduo, em quantidades adequadas, é viável na produção de tijolos modulares de resíduo-cimento, reduzindo o custo da produção, além de minimizar a degradação ambiental, causada pelos aterros e uso de recursos naturais, com o destino correto do resíduo.

\section{REFERÊNCIAS}

1 ASSOCIACAO BRASILEIRA DE CELULOSE E PAPEL. Relatório Estatístico Mensal. São Paulo: BRACELPA, 2011. 
ASSOCIAÇÃO BRASILEIRA DE NORMAS TÉCNICAS. NBR 6457: solo: preparação para ensaios de compactação e caracterização. Rio de Janeiro, 1986b.

3 ASSOCIAÇÃO BRASILEIRA DE NORMAS TÉCNICAS. NBR 6459: solo: determinação do limite de liquidez. Rio de Janeiro, 1984b.

4 ASSOCIAÇÃO BRASILEIRA DE NORMAS TÉCNICAS. NBR 6508: solo: determinação da massa específica. Rio de Janeiro, 1984b.

5 ASSOCIAÇÃO BRASILEIRA DE NORMAS TÉCNICAS. NBR 7180: solo: determinação do limite de plasticidade. Rio de Janeiro, 1984c.

6 ASSOCIAÇÃO BRASILEIRA DE NORMAS TÉCNICAS. NBR 7181: solo: análise granulométrica. Rio de Janeiro, 1984a.

7 ASSOCIAÇÃO BRASILEIRA DE NORMAS TÉCNICAS. NBR 8491: tijolo de solocimento: requisitos. Rio de Janeiro, 2012b.

8 ASSOCIAÇÃO BRASILEIRA DE NORMAS TÉCNICAS. NBR 10832: fabricação de tijolo maciço de solo-cimento com utilização de prensa manual. Rio de Janeiro, 1989.

9 ASSOCIAÇÃO BRASILEIRA DE NORMAS TÉCNICAS. NBR 10833: fabricação de tijolo e bloco de solo-cimento com utilização de prensa manual ou hidráulica: procedimento. Rio de Janeiro, 2012a.

10 ASSOCIAÇÃO BRASILEIRA DE NORMAS TÉCNICAS. NBR 10834: bloco vazado de solo-cimento sem função estrutural. Rio de Janeiro, 1994.

11 ASSOCIAÇÃO BRASILEIRA DE NORMAS TÉCNICAS. NBR 10836: bloco vazado de solo-cimento sem função estrutural: determinação da resistência à compressão e da absorção de água. Rio de Janeiro, 1994b.

12 CENTRO DE PESQUISA E DESENVOLVIMENTO. Cartilha para construção de paredes monolíticas em solo-cimento. 3ª Edição Revisada e Ampliada. Rio de Janeiro, BNH/DEPEA; 1984.

13 CENTRO DE PESQUISA E DESENVOLVIMENTO. Manual Prático de Construção em Solo-Cimento. Camaçari: BNH; Ceped, 1978.

14 FERRARI, V. J.; SOUZA, A. H. C.; BALTAZAR, H. P.; DOTTO, W.; VIEIRA NETO, J. G. Tijolos vazados de solo-cimento produzidos com solo da Região do Arenito Caiuá do Paraná. Ambiente Construído, Porto Alegre, v. 14, n. 3, p. 131-148, jul/set. 2014.

15 FERRAZ, R. L.; BELICANTA, A.; GUTIERREZ, N. H. M. Estudo comparativo de alguns métodos de dosagens de misturas solo-cimento. Editora EDUEM, Universidade Estadual de Maringá, Maringá, PR. 2000.

16 MILANI, A. P. da S.; BARBOZA, C. S. Contribuição ao estudo de propriedades do solocimento autoadensável para fabricação de paredes monolíticas. Ambiente Construído, Porto Alegre, v. 16, n. 4, p. 143-153, out/dez. 2016.

17 MILANI, A. P. da S.; LABAKI, L. C. Physical, Mechanical, and Performance of CementStabilized Rammed Earth-Rice Husk Ash Walls. Journal of Materials in Civil Enginnering, v. 24, n. 6, p. 775-83, 2008.

18 MONTE, M. A. V. Aplicação de Solo-cimento em Pavimentos Flexíveis. 101p. Dissertação (Mestrado em Engenharia Civil) - Universidade do Porto, Porto, Portugal, 2012.

19 PINHEIRO, M. L.; ALVARENGA, R. de C. S.; RIBEIRO, B. C.; SILVA JÚNIOR, P. R.; SARMET, M. S.; FASSONI, D. P. Avaliação experimental de blocos prensados de solocimento com adição de grits. Ambiente Construído, Porto Alegre, v. 13, n. 2, p. 29-46, abr./jun. 2013.

20 RODRIGUES, S.M. Adição de resíduo de argamassas mistas na produção de tijolos modulares de solo-cimento. 106p. Dissertação (Mestrado em Engenharia do Meio Ambiente, Recursos Hídricos e Saneamento Ambiental). Universidade Federal de Goiás, Goiás, 2008. 